\title{
ACTIVE ELECTRONIC PERSONAL DOSEMETER IN INTERVENTIONAL RADIOLOGY
}

\author{
I. Prlic ${ }^{1, *}$ M. Suric Mihic ${ }^{1}$ and Z. Vucic ${ }^{2}$ \\ ${ }^{1}$ Institute for Medical Research and Occupational Health, Unit for Radiation Dosimetry and Radiobiology, \\ Ksaverska Cesta 2, PO Box 291, HR 10000 Zagreb, Republic of Croatia \\ ${ }^{2}$ Institute of Physics, Bijenicka Cesta 46, HR 10000 Zagreb, Republic of Croatia
}

Received August 18 2008, revised October 21 2008, accepted October 302008

A recently developed active electronic personal dosemeter (AEPD) was utilised in order to measure the levels and the structure of occupational exposure to scattered X-ray radiation of medical staff who performed percutaneous revascularisation therapy that involves interventional radiology (IR) on the pelvis and upper leg arteries. The AEPDs, placed on the operators' and assistants' chests, that is, above the protective apron, continuously measured and recorded the received doses and, as a novelty, dose rates as a function of time, thus yielding a unique record of occupational doses and dose rates pattern at the working place. This paper presents and discusses one typical daily pattern in which seven percutaneous interventions were performed.

\section{INTRODUCTION}

In recent decades, passive dosemeters (film badge and thermoluminescent) have been extensively used for occupational exposure monitoring. Their physical properties and technical characteristics are well understood and they have successfully fulfilled measurement demands for many years ${ }^{(1)}$

However, modern technology progress and newly developed techniques and procedures, used in industry and medicine (medical imaging and therapy), are more demanding and require customised and upgraded occupational dosimetry. Occupational doses in diagnostic and interventional procedures in medicine range from very low to low doses (up to $50 \mathrm{mSv} \mathrm{y}^{-1}$ - a little above the recommended limit) ${ }^{(2)}$. These doses are related predominantly to scattered X-ray radiation. In such procedures, professionals are occasionally arbitrarily exposed to radiation with dose rates that vary from background (BG) $\left(80-130 \mathrm{nSv} \mathrm{h}{ }^{-1}\right)$ to 100 times higher ${ }^{(3-6)}$.

Passive dosemeters, film badges and TLDs, have some limitations, inabilities such as immediate dosereading, dose absorption time resolution and rereading after being read out.

Electronic personal dosemeters (EPDs) are designed to remove these limitations. Those that are sensitive enough in the very low dose region of professional exposures might be used to supplement passive dosemeters. Electronic dosemeters have been

*Corresponding author: iprlic@imi.hr in use for many years, but only recently have been considered as regular occupational monitoring dosemeters. New technologies have enabled electronic dosemeters to become small, low power consumption devices with high data acquisition performances and real-time measurement capabilities.

As explicitly stated by Luszig-Bhadra and Perle ${ }^{(1)}$, EPD can record doses that are almost up to three orders of magnitude lower (smaller) than those detected by passive dosemeters. Their sensitivity is of the order of 100 counts per $\mu \mathrm{Sv}$ and can reliably detect doses as low as $\sim 0.015 \mu \mathrm{Sv}^{(1,7)}$ within an hour, which is within the $\mathrm{BG}$ radiation range.

The EPD is very comfortable to wear, can be easily manipulated, provides an immediate readout option, and allows for real-time measurements with an early warning alarm in possible accidental exposure situations. All of these characteristics allow the worker and the radiation protection officer to optimise and minimise the radiation exposure for special types of jobs, especially in medicine. This is a direct contribution to the ALARA principle.

In this paper, the characteristics of the new active electronic personal dosemeter (AEPD), ALARA OD, are demonstrated (see www.alara.hr). It was utilised together with a film badge dosemeter to measure accumulated dose and dose rate time dependence during an exposure of the professional medical staff to scattered X-ray radiation while performing interventional radiology (IR) procedures. IR was chosen due to the fact that interventional

(C) The Author 2008. Published by Oxford University Press. All rights reserved

The online version of this article has been published under an open access model. Users are entitled to use, reproduce, disseminate, or display the open access version of this article for non-commercial purposes provided that: the original authorship is properly and fully attributed; the Journal and Oxford University Press are attributed as the original place of publication with the correct citation details given; if an article is subsequently reproduced or disseminated not in its entirety but only in part or as a derivative work this must be clearly indicated. For commercial re-use, please contact journals.permissions@oxfordjournals.org 


\section{PRLIC ET AL.}

radiologists are the most exposed sub-group among sub-specialties in diagnostic radiology ${ }^{(8)}$. While performing an IR procedure, the operator (OP), leading radiologist, or other individuals occasionally expose unprotected parts of her/his body (extremities) to the primary X-ray beam. Furthermore, at the same time, his/her whole body is exposed to indirect, scattered radiation. The IR occupational dose rate pattern or the time-dependent dose rate is not accessible with passive dosemeters. AEPDs ALARA OD were used to continuously measure and record dose and dose rate as a function of time. The results yielded a unique record of occupational dose and dose rates patterns in the working place during a typical workday in which seven different percutaneous interventions were performed. (The percutaneous approach is commonly used in vascular procedures. This involves a needle catheter getting access to a blood vessel, followed by the introduction of a wire through the lumen of the needle.)

\section{EXPERIMENTAL METHOD}

AEPDs ALARA OD, based on GM tube, are used. An AEPD records accumulated dose, starting time and the duration of each deliberately performed fluoroscopic X-ray exposure during the IR procedure, and it operates in two modes. In the normal or BG mode, it accumulates doses over a certain preset time interval (from $1 \mathrm{~h}$ to $256 \mathrm{~h}$, usually $8 \mathrm{~h}$ ) and records the dose (number of impulses) at the end of the interval. The second is the 'event' (E) mode where 'event' refers to any actual dose rate higher than the threshold that is set to 2 impulse per second i.e. 200-500 times the local BG (the average local BG dose rate reads from 80 to $130 \mathrm{nSv} \mathrm{h}^{-1}$ i.e. about 30 impulse per hour (0.011 impulse per second)). The device is in the BG mode for as long as the dose rate, tested every second, is below the preset threshold value (2 impulse per second). As soon as it exceeds the preset value, the AEPD switches to the $\mathrm{E}$ mode in which it records the time duration in seconds and the accumulated dose of the time interval. In other words, AEPD can record in detail the time sequence of the received accumulated dose. All the readout data: doses, exposure fractions, fraction time sequences, dates, cumulative doses, total number of impulses of GM tube, total time duration of measurements and calibration factors are continuously recorded. Moreover, the AEPD by ALARA OD has no-'turnoff'-option; it is active for as long as batteries live $(\sim 3 \mathrm{y})$.

The recordings were downloaded to a PC and processed using the ALARA OD software. BG was measured using the RS 131 Reuter Stokes highpressure ionising radiation monitoring chamber. The quality factor $Q=1$ for $\mathrm{X}$ rays was used. The
AEPDs were tuned and calibrated for $\mathrm{BG}$ energies and checked for X-ray energies at $\sim 70 \mathrm{keV}$, which is a standard calibration of common X-ray angiography units used in $\mathrm{IR}^{(9,10)}$. Quality control measurements were done on the conventional X-ray radiography unit prior to IR treatment of patients. In this study, the equipment and patients were regarded as secondary radiation sources emitting scattered X rays. Data were collected while performing percutaneous revascularisation therapy procedures on the pelvis and upper leg arteries.

\section{RESULTS AND DISCUSSION}

This article presents data recorded by ALARA OD - type of AEPDs ${ }^{(10-12)}$ worn as additional personal dosemeters ${ }^{(4,5,9)}$ by four medical specialists as shown in Figure 1. AEPDs were strapped on the protective apron, on the left side at the chest level ${ }^{(9,10)}$. In one working day, the four IR specialists performed or took part in seven IR procedures each lasting more than $30 \mathrm{~min}$ (Table 1).

During the working day, their roles changed from leading radiologist (OP1) to first-line assistant radiologist (A1). As OP1s, they received from 4.0 to $7.5 \mu \mathrm{Sv}$ per procedure while as A1s the received dose ranged from 0.3 to $1.4 \mu \mathrm{Sv}$ per procedure. In the rest of IR procedures, they were observers (A2), still near the patient table, but behind the OP1 and A1s. As A2s, they received from 0.1 to $0.3 \mu \mathrm{Sv}$ per procedure.

One additional AEPD was placed in the X-ray remote control room, properly shielded ${ }^{(2)}$ from scattered radiation behind the protective wall and windows. That room was not considered as a controlled area ${ }^{(2)}$ where the expected annual equivalent dose is $>1 \mathrm{mSv}^{(2,11,12)}$.

All AEPDs, strapped on the protective aprons hanging in the IR wardrobe room, were started at

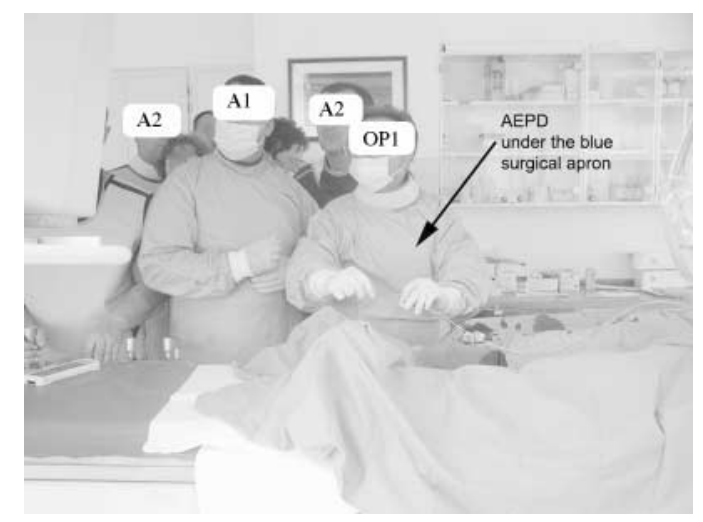

Figure 1. Arrangement of specialists performing IR procedure no. 1. 
Table 1. Timetable of IR procedures of a single specialist wearing ALARA OD no. 00204 and his role in a particular procedure.

\begin{tabular}{lcccc}
\hline IR procedure & IR time table & IR specialist's role & AEPD time operating in E mode (in s) & AEPD location \\
\hline & $0: 54-9: 00$ & & & $\mathrm{Wa}^{\mathrm{a}}$ \\
I & $9: 15-9: 55$ & OP1 & 245 & $\mathrm{Ap}^{\mathrm{b}}$ \\
II & $10: 20-11: 10$ & A1 & 62 & $\mathrm{Ap}$ \\
III & $11: 20-12: 55$ & A1 & 15 & $\mathrm{Ap}$ \\
IV & $13: 10-13: 45$ & A2 & 4 & $\mathrm{Ap}$ \\
& $13: 55-16: 00$ & Lunch break & 313 & Wa \\
V & $16: 05-16: 55$ & OP1 & 15 & $\mathrm{Ap}$ \\
VI & $17: 20-18: 57$ & A1 & 198 & $\mathrm{Ap}$ \\
VII & $19: 10-19: 55$ & OP1 & & $\mathrm{Ap}$ \\
& $20: 00-00: 26$ & & & Wa \\
\hline
\end{tabular}

${ }^{\mathrm{a}} \mathrm{Wa}$, wardrobe.

${ }^{\mathrm{b}} \mathrm{Ap}$, strapped on the apron/front.

1:00 a.m. ( $\pm 5 \mathrm{~min})$. They were started early enough in order to properly measure the $\mathrm{BG}$ radiation. AEPDs have measured $\mathrm{BG}$ from starting time to the beginning of IR procedures and the results were in agreement with the RS131 ionising chamber's BG. At 8:00 a.m., IR specialists put on protective aprons and wore them throughout the working day, except for the lunch break $(\sim 2 \mathrm{~h})$, while the aprons were left hanging in the X-ray wardrobe room. The leading radiologist (OP1) performed four percutaneous revascularisation therapy interventions of various durations. He also took part in three other interventions, either as $A_{1}$ or $A_{2}$ assistant. He spent the rest of his working time outside the operating room. The timetable of performed IR procedures and the position of the particular radiologist (OP1 in first procedure) and the dosemeter assigned to him are given in Table 1.

There were four IR procedures in the morning shift, from 9:15 to 13:45, and three in the afternoon shift, from 16:05 to 19:55. Lunch break time was from 13:55 to 16:00. From 1:00 a.m. to 00:30 a.m. of the next day, the AEPDs were continuously measuring local BG (total measuring time was $23.5 \mathrm{~h}$ ).

The total number of impulses recorded by different AEPDs during that day, varied from 1467 for the radiographer to the relatively wide range of recorded impulses, ranging from 3017 to 11332 impulses, for other medical staff members involved in the procedures. The corresponding total equivalent doses were 4.4, 10.9 and $33.2 \mu \mathrm{Sv}$, respectively. The readout intervals and IR procedure events are shown in Figure 2 and Tables 1 and 2. Figure 2 shows two types of records. The lowest, the radiographer's AEPD record (r), shows increasing linear time dependence of accumulated dose in agreement to being exposed to $\mathrm{BG}$ radiation solely $(4.4 \mu \mathrm{Sv})$. During the IR procedures, this AEPD operated exclusively in the BG mode, which demonstrates that

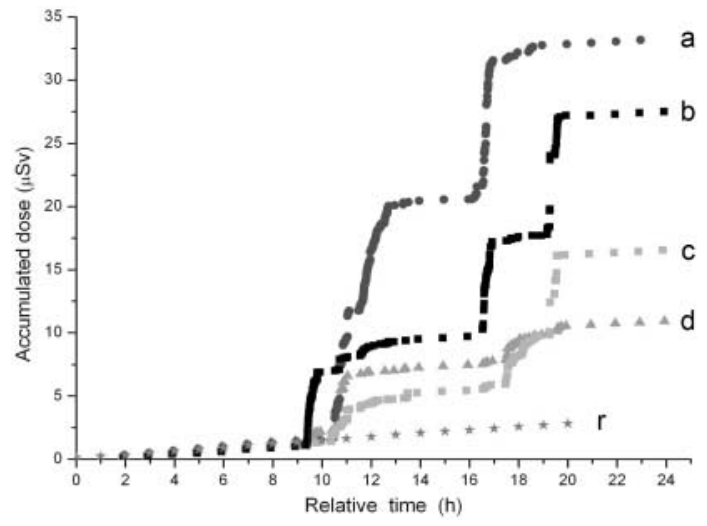

Figure 2. Accumulated dose readout of five AEPDs (ALARA OD type) continuously measuring either in BG mode or in E mode - four IR radiologists ( $\mathrm{a}, \mathrm{b}, \mathrm{c}$ and $\mathrm{d}$ ) and one radiographer (r). Recordings refer to one working day, including seven vascular IR procedures. Preset time interval was $1 \mathrm{~h}$. Preset threshold value for switching into E mode was $2 \mathrm{imp} \mathrm{s}^{-1}$. Curve $\mathrm{r}$ shows the dose accumulated in the control room.

the remote control room was properly shielded from radiation. The other type of records was done by AEPDs worn by the operators. The dose accumulation curves ( $a, b, c$ and d) exhibit a step-like behaviour. Each step, representing a steep increase in the accumulated dose, is related to a particular IR procedure involving an intensified fluoroscopy regime. Figure 3 shows equivalent dose rates for the first morning intervention starting at 9:15 a.m. $(I)$ as a function of time. Presented sequence of dose rate values were obtained by dividing the dose accumulated during each of $\mathrm{E}$ mode intervals by the time duration of corresponding interval. Each single dose rate is the average of recordings obtained for each interval in which AEPDs were operating in E mode. 


\section{PRLIC ET AL.}

Table 2. Data readout for the AEPD strapped on the apron of the leading IR operator (b) during all seven IR procedures.

\begin{tabular}{ll}
\hline & \\
Dosemeter number & ALARA OD 02204 \\
User & IR (operator b in Fig.2) \\
Starting time & 28 September 2005-00:54:00 \\
Readout time & 29 September 2005-00:26:00 \\
Total dose & $27.6 \mu \mathrm{Sv}$ \\
Total number of impulses & 8295 \\
Total time & $23.5 \mathrm{~h}$ \\
\hline
\end{tabular}

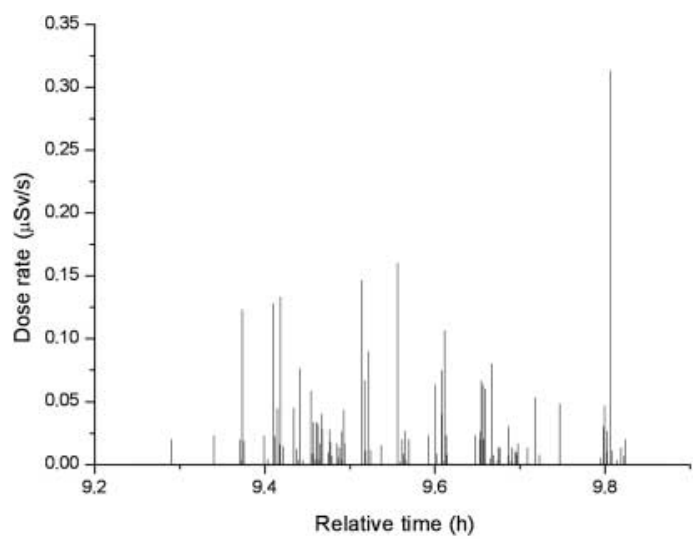

Figure 3. Dose rate recorded by the ALARA OD AEPD (average of 99 recorded $\mathrm{E}$ mode time intervals) over time during the first (of seven) vascular IR procedures (BG is not subtracted) performed by the leading operator (OP1). Bars denote the values of 99 during which fluoroscope was switched on. Total fluoroscopy time (AEPD in E mode) was $245 \mathrm{~s}$.

Time coordinate of the particular interval is ascribed to the end of the interval.

Although occupational equivalent dose rates were very low (not exceeding $0.3 \mu \mathrm{Sv} \mathrm{s}^{-1}$ ), due to relatively numerous fluoroscopic exposures ( 99 of them in the first morning intervention), the accumulated dose of $5 \mu \mathrm{Sv}$ was obviously not negligible. On closer inspection, the first intervention $(I)$ of the day shows that the OP1 (curve b in Figure 2) made extensive use of $\mathrm{X}$-ray fluoroscopy, which reflects either his characteristic therapeutic approach or the 'fingerprint' of a specific vascular therapy procedure. The total duration of exposure (exposure burden of medical specialist, i.e. AEPD in E mode) over the 40 min of the intervention was $245 \mathrm{~s}$ ( $12 \%$ of total time). The total equivalent dose recorded by the OP1's AEPD (b) over the entire monitoring time of $23.5 \mathrm{~h}$, received in 283 random fractions, was $27.6 \mu \mathrm{Sv}$. It reveals very low X-ray exposure. The obtained equivalent doses for the leading operator (OP1) per procedure (Table 1 and Figure 2) are in the range of $4.0-7.5 \mu \mathrm{Sv}$, which could be extrapolated to annual equivalent doses in the range of $3.2-6.0 \mathrm{mSv}$ ( $800 \mathrm{IR}$ procedures per operator per year). These values are in agreement with literature data for radiologists in vascular IR procedures $^{(4,13)}$ and about one-third of the value declared for the cardiologists' occupational doses ${ }^{(3,4,14)}$ as generally expected ${ }^{(9)}$. During the working day followed in the study, all IR specialists were wearing additional, one-day film dosemeters, but these did not record enough radiation to be interpreted correctly. The AEPD ALARA OD is capable of measuring and recording accumulated doses as a function of time, in ranges from very low to low doses, even in time intervals that are too short for passive dosemeters to make records with acceptable statistical significance.

From the analysis presented above, it may be concluded that the AEPD ALARA OD can be utilised as an additional personal dosemeter device for performing more accurate occupational exposure measurements than is possible by using passive dosemeters, due to the fact that ALARA OD can distinguish occupational dose contributions to the $\mathrm{BG}$ radiation. Moreover, ALARA OD is able to record characteristic dose rates of any single IR procedure.

Health surveillance and radiation protection of medical specialists performing IR intervention have to be additionally optimised and approved. Some medical specialists performing IR procedures, outside radiological units in hospitals, are often not recognised as occupationally exposed ${ }^{(9,15-19)}$.

ALARA OD dosemeter records can be utilised to improve dosimetry documentation and to optimise radiation protection facilities, education and training.

\section{CONCLUSIONS}

Occupational doses received by the medical staff performing IR procedures on the pelvis and upper legs arteries are referred to in literature in a surprisingly wide range of values $(0.2-18.8 \mu \mathrm{Sv}$ per procedure $)^{(13)}$. In order to improve and upgrade radiation protection of medical professionals, assuming usual IR procedure conditions, more accurate and reliable measurements of their exposure to scattered X-ray radiation (from a patient, medical equipment and air) appear to be urgently needed. Moreover, otherwise very low doses may, due to the frequent use of IR procedures (by leading medical specialists), exceed the recommended annual limits without being actually detected ${ }^{(6)}$.

It is shown that the ALARA OD AEPD can continuously and precisely measure local $\mathrm{BG}$ and at the same time record additional gamma- and X-ray radiation. ALARA OD AEPD will automatically record all segments of occupational radiation in IR.

Besides, a new type of readouts has been obtained, not reported in the literature so far. Namely, ALARA OD AEPD can produce a detailed record of characteristic dose rate time pattern of any single IR 
procedure. It would be worthwhile to submit it to a Regulatory Authority for approval in special (intervention), additional (nuclear medicine), or even regular personal dosimetry in the future.

\section{ACKNOWLEDGMENTS}

The authors would like to specially thank the medical staff of the Radiology Department of the Public Hospital 'Dr J. Bencevic', Slavonski Brod and to the leading IR specialist O. Rubin. The authors wish to thank N. Kovacevic for carefully reading the manuscript and for helpful suggestions. Patients were not intentionally exposed for the purpose of the research.

\section{FUNDING}

This work was supported, and funding to pay the Open Access publication charges for this article was provided by Ministry of Science, Education and Sports of the Republic of Croatia as a part of the research project Environmental Radioactivity and Radiation Protection.

\section{REFERENCES}

1. Luszig-Bhadra, M. and Perle, S. Electronic personal dosemeters will replace passive dosemeters in the near future. Radiat. Prot. Dosim. 123(4), 546-553 (2006).

2. International Atomic Energy Agency. International basic safety standards for protection from ionizing radiation and for the safety of radiation sources. Safety Series No. 115 (Vienna: IAEA) (1996).

3. Vaño, E., Gonzales, L., Fernandez, J. M., Alfonso, F. and Macaja, C. Occupational radiation doses in interventional cardiology: a 15-year follow up. Br. J. Radiol. 79, 383-388 (2006).

4. Tsapaki, V., Kottou, S., Patsilinakos, S., Voudris, V. and Cokkinos, D. V. Radiation dose measurements to the interventional cardiologist using an electronic personal dosemeter. Radiat. Prot. Dosim. 112(2), 245-249 (2004).

5. Vaño, E., Gonzales, L., Guibelalde, E., Fernandez, J. M. and Ten, J. I. Radiation exposure to medical staff in interventional and cardiac radiology. Br. J. Radiol. 71, 954-960 (1998).

6. Carabajo, J., Baeza, I., Gonzales, I., Herrador, M. and Luis, F. J. Occupational dosimetry in digital and conventional vascular/interventional radiology 2000. In: Proceedings of 11th International Congress of the International Radiation Protection Association, Spain, SRPS, Madrid, Spanish Radiation Protection Society 23-28 May (2004).

7. Bolognese-Milsztajn, T., Ginjaume, M., LuszikBhadra, M., Vanhavere, F., Wahl, W. and Weeks, A. Active personal dosemeters for individual monitoring and other new developments. Radiat. Prot. Dosim. 112(1), 141-168 (2004).

8. Al-Haj, A. N., Lagarde, C. S. and Lobriguito, A. M. Variation of occupational doses among subspecialities in diagnostic radiology. In: Proceedings of 11 th International Congress of the International Radiation Protection Association, Spain, SRPS, Madrid, Spanish Radiation Protection Society 23-28 May (2004).

9. World Health Organization. Efficacy and Radiation Safety in Interventional Radiology (Geneva, Switzerland: WHO) (2000).

10. International Commission on Radiological Protection. Avoidance of radiation injuries from medical interventional procedures. ICRP Publication 85. Ann. ICRP 30(2) (Oxford, UK: Pergamon Press, Elsevier Science Ltd) (2000).

11. International Commission on Radiological Protection. Annals of the ICRP 1990 recommendations. ICRP Publication 60. 21(1-3) (Oxford, UK: Pergamon Press, Elsevier Science Ltd) (1990).

12. United Nations Scientific Committee on the Effects of Atomic Radiation. UNCSEAR 2000 report to the general assembly with scientific annexes Vol. I-II (New York: UN Publications) (2000).

13. Siiskonen, T., Tapiovaara, M., Kosunen, A., Lehtinen, M. and Vartiainen, E. Occupational radiation doses in interventional radiology: simulations. Radiat. Prot. Dosim. 129, 36-38 (2008).

14. International Atomic Energy Agency. Assessment of occupational exposure due to external sources of radiation. Safety Series. Safety Guide RS-G-1.3 (Vienna: IAEA, ILO) (1999).

15. Prlic, I., Suric Mihic, M., Mestrovic, T., Vucic, Z. and Cerovac, Z. 'ALARA OD' active electronic personal dosemeter-implementing a new concept in radiation dosimetry (Book of abstracts). In: 10th International Symposium on Radiation Physics, Coimbra, Portugal, 17-22 October (2006).

16. Prlic, I. et al. Digital dosemeter 'ALARA OD2'-'Ort' and personal dosimetry. In: Proceedings of International Conference on Occupational Radiation Protection: Protecting Workers against Exposure to Ionizing Radiation (IAEA, ILO, EU, OECD/NEA, WHO), Geneva, Switzerland (IAEA, Wienna) pp. 219-224 (2002).

17. Prlic, I. et al. Digital dosemeter ALARA OD2. In: Medizinische Physik 2001. Proceedings of 32 Wissenschaftlische Tagung der Deutschen Gesselschaft fuer Medizinische Physik, DGMP, Berlin (2001).

18. Prlic, I., Suric Mihic, M., Milkovic-Kraus, S., Mestrovic, T. and Rojnica, F. Characterization of workplaces in interventional radiology using active dosemeters ALARA OD (Book of abstracts). In: IM 2005European Workshop on Individual Monitoring of Ionizing Radiation, Vienna, Austria (2005).

19. Prlic, I., Suric Mihic, M., Milkovic-Kraus, S., Mestrovic, T. and Vrtar, M. Characterization of workplaces in interventional radiology using active dosemeters ALARA OD. Radiat. Prot. Dosim. 125(1-4), 379-382 (2007). 